\title{
Pulmonary Lobule
}

National Cancer Institute

\section{Source}

National Cancer Institute. Pulmonary Lobule. NCI Thesaurus. Code C33428.

The smallest anatomical unit of the lung, measuring 0.50 to $2.00 \mathrm{~cm}$ in diameter. Each lobule is composed of 4-8 terminal bronchioles and their distal alveolar ducts and sacs. The lobules are separated by fibrous interlobular septa. 